\title{
Prosodic Transfer: From Chinese Lexical tone to English Pitch Accent
}

\author{
Marie Ploquin \\ University of Quebec in Montreal \\ DeSeve-2413 \\ 320, Sainte-Catherine East \\ Montreal (Quebec) \\ H2X 1L7 \\ Tel: (514) 987-3000 Ext:4791 \\ E-mail: ploquin.marie@uqam.ca
}

Doi:10.7575/aiac.alls.v.4n.1p.68

URL: http://dx.doi.org/10.7575/aiac.alls.v.4n.1p.68
Received: 01/12/2012

Accepted: 05/01/2013

\begin{abstract}
Chinese tones are associated with a syllable to convey meaning, English pitch accents are prominence markers associated with stressed syllables. As both are created by pitch modulation, their pitch contours can be quite similar. The experiment reported here examines whether native speakers of Chinese produce, when speaking English, the Chinese tone whose phonetic contour most closely matches the contour of the intended English pitch accent. Six native speakers of Chinese recorded English and Chinese sentences, all including the segment [fan]. Results show that the subjects produced a Chinese tone 2 where a rising pitch accents was required and thus that speakers of Chinese rely on their lexical tones inventory to produce English prosody. The results obtained with falling pitch accents are much less conclusive partly because of the difficulty in measuring tone 3 due to the high level of creak that accompanies it.
\end{abstract}

Keywords: Chinese; English; lexical tone; pitch accents, tone transfer;

\section{Introduction}

The influence of first language (henceforth L1) phonology and phonetics onto second language (henceforth L2) pronunciation has been the subject of a fair amount of research. While the majority of papers explore the L2 production of segments, a few, more recent articles, investigate prosody. Some of the latter look into stress placement, either at the phrase or at the lexical level (see, e.g., Anani (1989) on English lexical stress Jordanian Arabic learners; Guion, 2005, on English stress by native speakers of Korean speakers; Ploquin, 2009, on English rhythm and lexical stress second language English by native speakers of two varieties of French; Kijak, 2009, on the production of Polish stress by native speakers of Russian, Czech, German, English, French, Spanish, Italian and Chinese). Other studies measure prosodic correlates - fundamental frequency (F0) or duration or intensity - produced by native or non-native speakers of a language (see e.g. Ueyama (2000) on first and second language English and Japanese; Guilbault (2002) on French produced by native speakers of English; Hua (2003) on English prosody by Taiwan Mandarin ESL learners). Phonetic contours have also been studied by a few authors, mostly as description of intonation patterns (see, e.g. Swerts and Zerbian, 2010, on ESL intonation by speakers of Zulu; Mennen, 2004, on bidirectional Dutch Greek intonation) while a handful look into pitch accents (see notably Saito and Ueda (2007) for English pitch accent patterns by native speakers of two varieties of Japanese).

Regardless of the phonetic features and languages studied, cross-language research usually evaluates a same feature in both L1 and L2. This includes comparative studies that examine features in one tone language and one non-tone language. The production and perception of tones by native speakers of a non-tone language has been studied (see e.g. Bent, 2005; Wang, Jongman, and Sereno, 2006; Guion and Pederson, 2007). However, the possible influence of tones of a tone language on the production or perception of intonation or pitch accents in another language has scarcely been investigated. Only two studies closely address the issue. Nguyen et al's (2008:1) study reports that "Vietnamese speakers had no problem in manipulating contrastive levels of f0 and intensity on accent-bearing syllables but failed to realize the timing contrast between compound words and phrases and the syntagmatic contrast of accent in larger units". Chen's (2007:1648) paper concludes that "Native speakers of Chinese learning Spanish seem to interpret Spanish stress as a combination of a rising and a falling tone". If it is the case that speakers of a tonal language perceive tones in nontonal languages, one may wonder if speakers of a tonal language also use tones in their production of non-tonal languages. The experiment reported here examine this possibility with regards to native speakers of Chinese producing English (ESL). So, the question investigated here is "do native speakers of Chinese use Chinese tones in their production of English pitch accents?" Certainly, phonologically speaking, pitch accents of English are tones. Both tones and pitch accents are tonal patterns, that is to say, pitch modulation. However, unlike pitch accents, Chinese tones 
are associated with a syllable (in some African and Scandinavian languages, the tone can be associated with a word rather than a syllable, sometimes to indicate a grammatical function). Pitch accents are instead assigned to prominent or stressed syllables, according to the language's (usually not a tone language) phonology. Pitch accent and tones also differ in their phonetic production. First, the phonetic pitch range of Chinese tones is greater than that of English rhythm.

"[Chen's (1974)] results show that the average pitch range of the native Chinese speakers speaking Chinese was 1.5 times wider than that of the English speakers when they spoke English" (Wang, Jongman, and Sereno, 2006)

Second, Chinese tones require a specific use of the tonal space while English pitch accents are adjusted by each speaker. The difference between speakers who use a narrow pitch range and those who use a wider pitch range in English is generally understood to reflect personality and mood (for instance, timid or bored for the former, outgoing or excited for the latter). In English, greater or narrower pitch range does not however hinder comprehension of the message. In Chinese, not respecting the traditional use of tonal space creates comprehension problems. For example, learners of Chinese as a second language make as many tonal space errors as contour errors. Miracle (1989) found that L2 learners of Chinese produced tones 1 and 4 too low in the tonal space and tones 2 and 3 too high in the tonal space. This shows that in Chinese, tone pitch height and pitch range are standardized.

$\mathrm{SC}$ tones can be described and noted in different ways, as shown in table 1 below.

Table 1. Comparative presentation of the notation of SC tones

\begin{tabular}{l|l|l|l|l}
\hline & $\begin{array}{l}\text { AM } \\
\text { notation }\end{array}$ & Tone shape & $\begin{array}{l}\text { Chao tone } \\
\text { digits }\end{array}$ & $\begin{array}{l}\text { Pinyin notation } \\
\text { (on "ma") }\end{array}$ \\
\hline $1^{\text {st }}$ tone & H & High & 55 & mā \\
\hline $2^{\text {nd }}$ tone & LH & High rising & 35 & má \\
\hline $3^{\text {rd }}$ tone & L(H) & Low falling (rising) & $21(4)$ & mă \\
\hline $4^{\text {th }}$ tone & HL & High falling & 51 & mà \\
\hline
\end{tabular}

Chao's (1930) tone digits are used to refer to the tonal space by means of numbers. The numbers are those found in the graphic representation of tones (see figure 1a) in which 1 represents the lowest level and 5 the highest level. Tone digits 55 thus indicate that the tone (tone 1) starts high and remains high while 51 indicate that the tone (tone 4) starts high and ends low, making it a high falling tone. While Tone 3 is typically described and sketched as a low falling rising tone (214), a number of studies has shown that this tone is actually a low falling tone (21) which can get a rising part in particular circumstances, such as in the citation form or in final position of an interrogative sentence (see Shen 1990, Lee 2005). For this reason, it is sometimes noted 21(4). Figure $1 \mathrm{~b}$ thus offers a more accurate representation of Chinese tones as native speakers normally realized them.

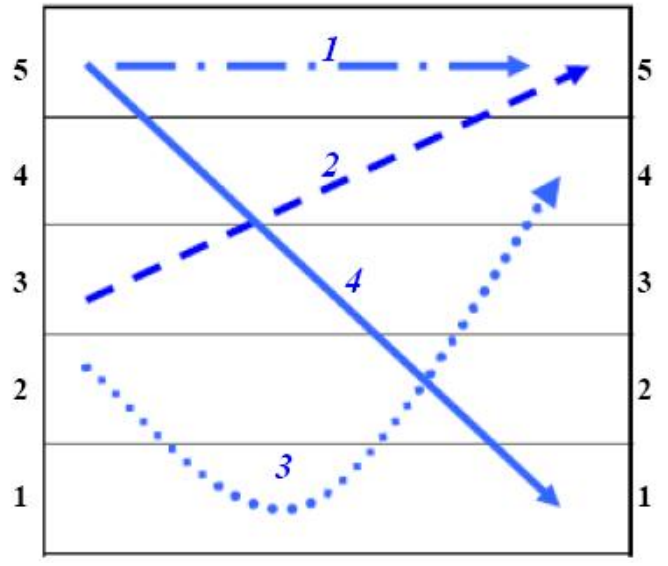

Figure 1a. Graphic representation of the four Chinese tones with tone 3 as a low falling rising tone

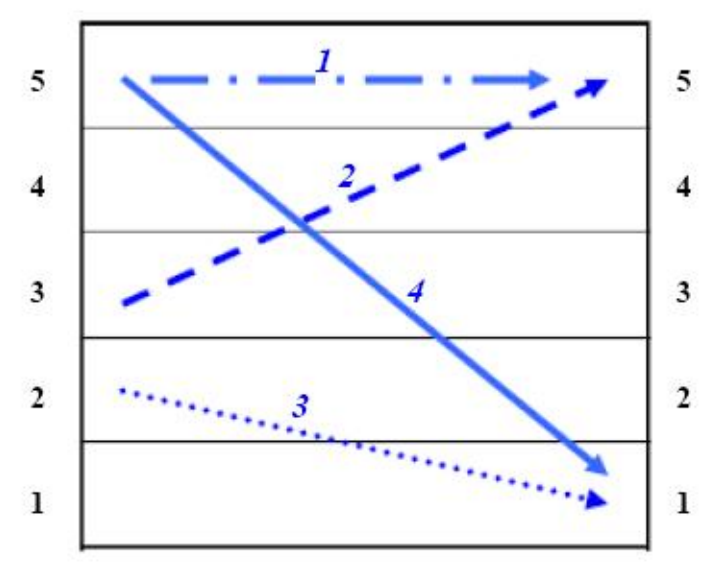

Figure 1b. Graphic representation of the four Chinese tones with tone 3 as a low falling tone

Graphic description of the tones' tonal space is highly convenient to compare the four tones but, as there is no reference to measurable correlates (such as fundamental frequency or semitones), relating tones to pitch accents is particularly challenging. For this reason, in this experiment, the speech of the same native speakers of Chinese is compared for their production of pitch accents in English and their comparable tones in Chinese. This is done by comparing the 
pronunciation of the English word "fan" in different sentential contexts and the production of a variety of [fan ${ }^{\text {tone }}$ ] in Chinese.

\section{Materials and Methods}

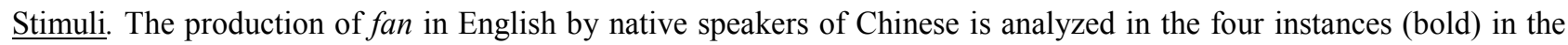
sentence below:

\section{There are three fans: a black fan, a white fan, and a red fan.}

The production of [fan] in Chinese by native speakers of Chinese is analyzed in the twenty instances. These include each word, that is to say the segment [fan] with one of the four tones (i.e. fān, fán, fãn, fàn) in five sentential contexts to allow for a possible variation in phonetic production of a same tone according to its position in the sentence. In the first sentence, the word was sentence initial (position A); in the second, mid sentence; in the third, affirmative final; in the fourth, pre-pause; and in the fifth, interrogative final (see appendix A).

Procedures. All subjects were recorded individually in a computer lab using computers equipped with Creative Technology "Sound blaster live" sound cards and Sony HS-90B combined headphone and microphone headsets. All sentences were digitally recorded using Can8 Virtual Lab. The subjects were shown how to use the equipment and how to best adjust the volume of their recording.

The English target sentence was presented on a computer monitor. A picture illustrating the sentence was provided to help understanding. The sentence was one of fourteen sentences the subjects had to record. The Chinese target sentences were presented in Chinese, without illustration, and after the English sentences.

\section{Subjects ${ }^{1}$ :}

Six native speakers of North American English (1 male and 5 female) provided the control recordings. Seven native speakers of Chinese ( 1 male, 6 female) participated as subjects with a mean age of 37.5 years $(\mathrm{SD}=2.93)$. All the subjects were all students in the English programs at University of Quebec in Montreal. All had completed their previous studies in China and had studied an average of 6.5 years (SD: 4) of English as a second language.

\section{$\underline{F_{0}} \underline{\text { measurements and extraction }}$}

For each production of fan in English and in Chinese, pitch level was measured in semitones at the 10\%, 30\%, 50\%, $70 \%$, and $90 \%$ marks of the voiced part. The analysis was conducted with a program written to work with Praat. When the pitch level was outside the defined bracket or when there is no voicing - which happens with creaky voice -, the measure returns as "undefined". For the experiment, if one of the measures returned as "undefined", the pitch was measured manually moving away from the target to the nearest reading. For instance, if the $30 \%$ mark returned as undefined, a measure was searched for at $29 \%, 31 \%, 28 \%, 32 \%$, and so on. If no measure was available half way to the next target (on our example, $20 \%$ and $40 \%$ ), no measure was entered.

\section{$\underline{\text { Data }}$}

The English sentence "There are three fans: a black fan, a white fan, and a red fan.", was produced by native speakers of English (henceforth NS) and native speakers of Chinese (henceforth SC). The pitch accents produced by the two groups on each of the four occurrences of the word "fan" are illustrated in figures 2 and 3 . Henceforth, the first occurrence of "fan" is referred to as "fan1", the second as "fan2", the third as "fan3" and the fourth as "fan4".

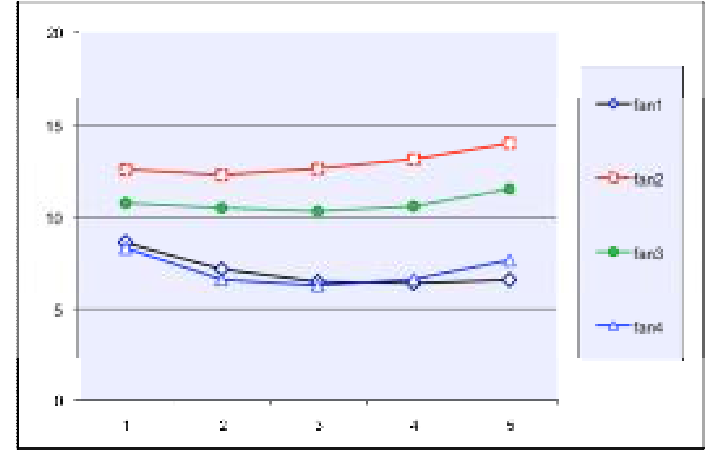

Figure 2. Average $\mathrm{F}_{0}$ in semitones at $10 \%$, $30 \%, 50 \%, 70 \%, 90 \%$ of the syllable "fan" in the four occurrences of the word in the sentence produced by native speakers of English

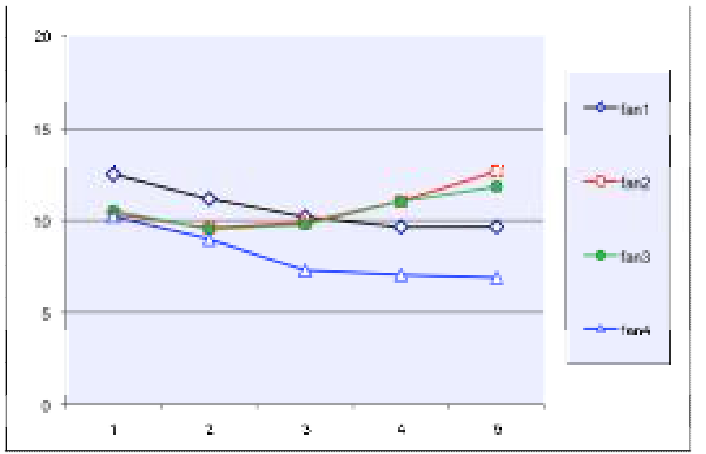

Figure 3. Native speakers of Chinese average $\mathrm{F}_{0}$ in semitones at $10 \%, 30 \%, 50 \%, 70 \%, 90 \%$ of the syllable "fan" in the four occurrences of the word in the sentence.

\footnotetext{
${ }^{1}$ The data from all of the Chinese subjects and from some of the Native speakers were used in Ploquin (2009:139). For the present paper, only the subjects whose recordings were not hindered by creak were selected. New native speakers were also recorded to gather creak-free recordings.
} 
From figures 2 and 3 we can observe that the NS produced fanl and fan 4 with an almost identical contour and at the same level. The SC also produced fan 1 and fan 4 with an almost identical contour but produced fan 4 at lower pitch levels than they produced fan1. While the contour used by NS is a falling-slightly rising contour, SC used a falling-flat contour. NS produced fan 2 and fan 3 with an almost identical contour but produced fan 2 at a higher pitch level than they produced fan3. The SC also produced fan 2 and fan 3 with an almost identical contour but produced both fan 2 and fan 3 at the same pitch level and the two contours are virtually superimposed. Both groups used a slightly-rising contour on those words.

The Chinese speakers' production of fan 1 and fan 4 will be compared to a rising Chinese tone while their production of fan 1 and fan 4 will be compared to a low falling Chinese tone. This study therefore considers both the shape and the F0 range used to produce tonal contours.

\section{Results and Discussion}

Flege's (1995) Speech Learning Model specifies that similar L1 and L2 features are not as easily acquired as features that are very different. Taking this model as theoretical basis, it was hypothesized that native speakers of Chinese might transfer tones 2, 3, 4 to produce rising, low falling and high falling pitch accents respectively. Tone 1 could be predicted to be transferred into English where a high flat contour is produced but this is a rare occurrence as no such pitch accent is listed (Taylor, 1992) although it could be produced as a combination of pitch and boundary tones, probably in a conversation. More specifically, bearing in mind the contours produced by native speakers for the four instances of "fan" (figure 2 above) and the prototypical shapes of Chinese tones (figures 1a and 1b above), one could hypothesize that native speakers of Standard Chinese would produce fan 1 and fan 4 as tone 2 and fan 2 and fan 3 as tone 3 (in its low falling form).

Figures 4 to 7 show the production of fān (tone 1), fán (tone 2), fãn (tone 3), fàn (tone 4) respectively by the seven subjects taking part in the study. Each graphic includes the combined production of the SC for each tone in the different situations: A: sentence initial; B: mid sentence; C: affirmative final; D: pre-pause; E: interrogative final.

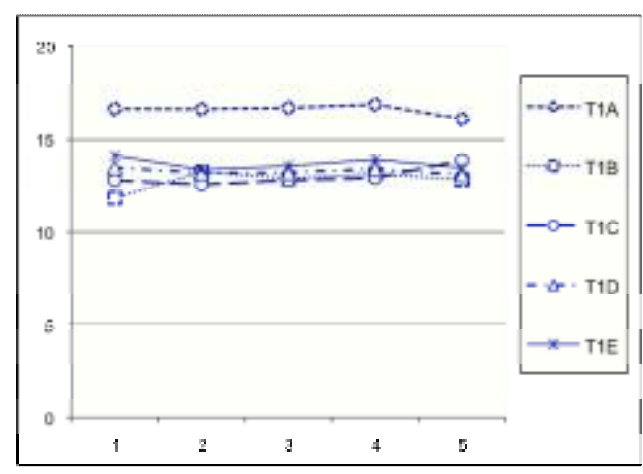

Figure 4. Chinese speakers' average $\mathrm{F}_{0}$ in semitones at $10 \%, 30 \%, 50 \%, 70 \%$, $90 \%$ of the word "fān" in five sentential positions.

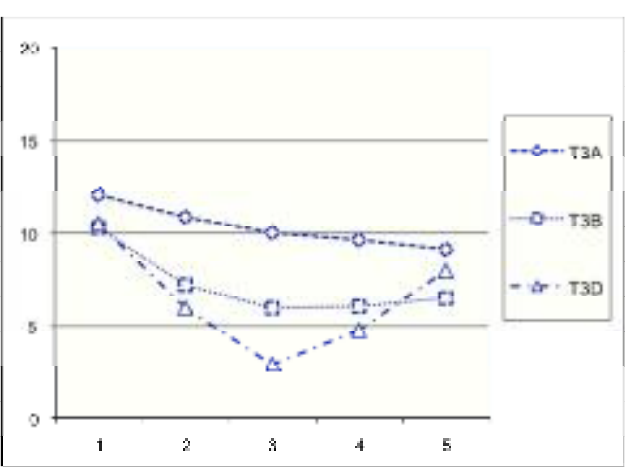

Figure 6. Chinese speakers' average $\mathrm{F}_{0}$ in semitones at $10 \%, 30 \%, 50 \%, 70 \%$, $90 \%$ of the word "fãn" in five sentential positions. The dip is at least partially created by the absence of F0 around the $50 \%$ mark because of creakiness.

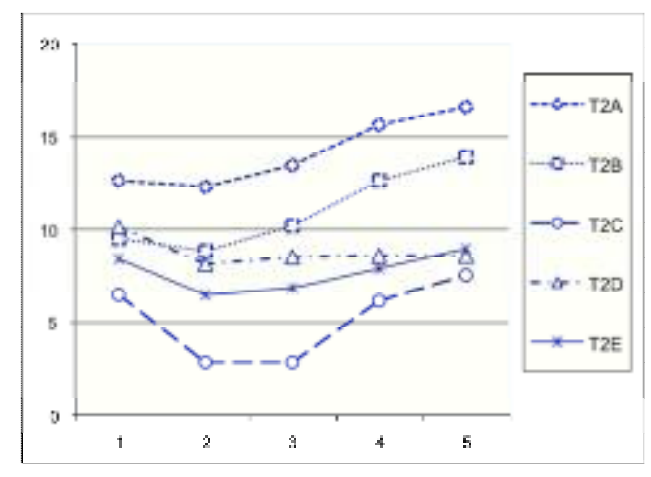

Figure 5. Chinese speakers' average $\mathrm{F}_{0}$ in semitones at $10 \%, 30 \%, 50 \%, 70 \%$, $90 \%$ of the word "fán" in five sentential positions.

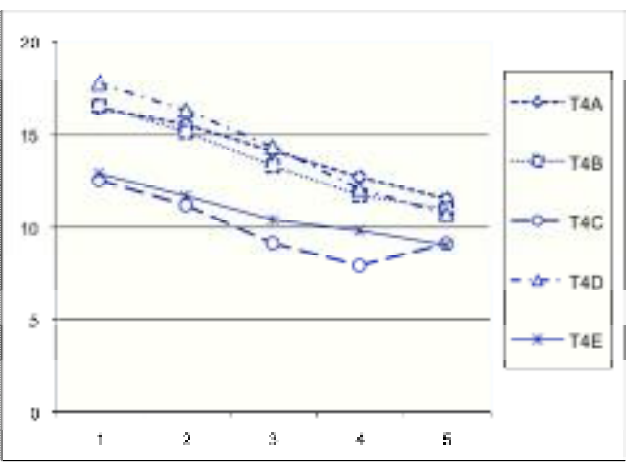

Figure 7. Chinese speakers' average $\mathrm{F}_{0}$ in semitones at $10 \%, 30 \%, 50 \%, 70 \%$, $90 \%$ of the word "fàn" in five sentential positions. 
One can observe that although pitch level varies according to the place of the segment in the sentence, the shape of the tone varies very little. The exception is tone 3 which is a falling tone in situations $\mathrm{A}$ and $\mathrm{B}$, falling rising in situation $\mathrm{D}$. The contours of tone 3 in positions $\mathrm{C}$ and $\mathrm{E}$ are not drawn in the graph because the high amount of creak produced, particularly in the middle of tone, prevented reliable F0 extraction. In fact, tone 3 is notoriously difficult to measure because of the creakiness that accompanies the lower frequencies of this tone (Keating and Esposito, 2007). The speakers selected for this study were chosen precisely because they produced very little creak compared to most speakers. In other words, these speakers did not produce creak in any situation other than certain forms of tone 3 . If we look at the measurements that could be collected for tone 3 in positions $C$ and $E$ (figures 8 and 9) we can see that the data is meager and disparate, whose average (dotted line) does not accurately represent the perceived contours. From these figures, we can however observe a fall at the beginning of the tone and a rise at the end of it. This is consistent with the notion of the falling-rising contour associated with tone 3. Furthermore, as creakiness is associated with lower frequencies, the absence of measurements in the middle of the tone indicates that the contour dips even more, which further validates the hypothesis of a falling-rising contour.

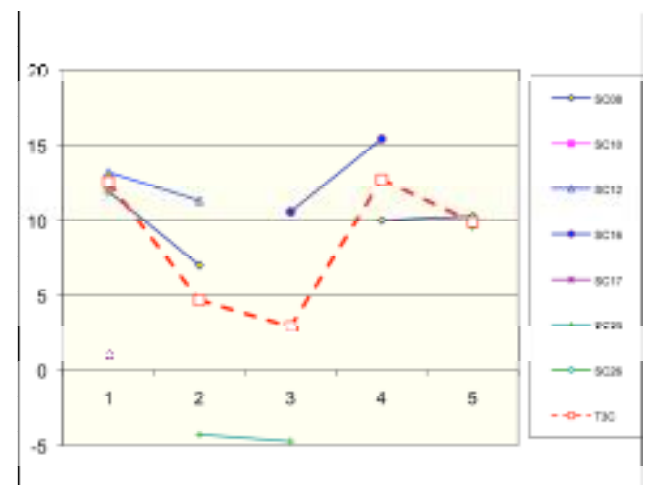

Figure 8. $\quad \mathrm{F}_{0}$ in semitones at $10 \%, 30 \%$, $50 \%, 70 \%, 90 \%$ of the word "făn" in position $\mathrm{C}$ (end of declarative sentence) for all speakers. Average contour in dotted line. The dip is created by the absence of F0 caused by creakiness.

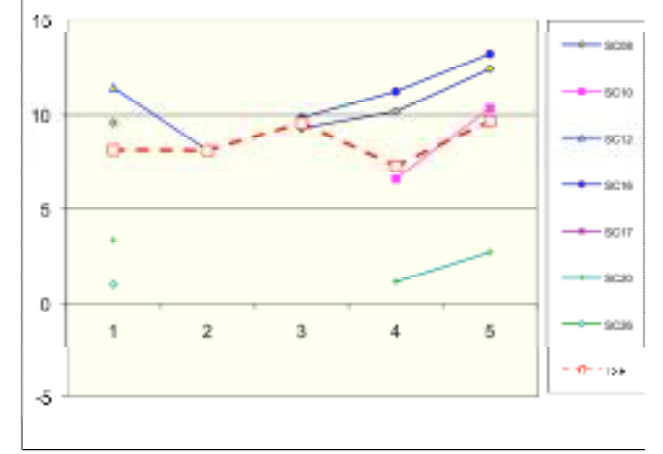

Figure 9. $\mathrm{F}_{0}$ in semitones at $10 \%, 30 \%, 50 \%$, $70 \%, 90 \%$ of the word "făn" in position $\mathrm{E}$ (end of interrogative sentence) for all speakers. Average contour in dotted line. The dip is created by the absence of F0 caused by creakiness.

In Ploquin (2009) an analysis at the micro level showed that some Chinese speakers' speech idiosyncrasies were present in their production of the segment "fan" in the English and the Chinese sentences. This corroborates the relation between tones and pitch accent contours in Chinese speakers' production. In the present paper, each speaker's production of fan 2 and fan 3 will be compared to the same speaker's production of tone 2 and his/her production of fan 1 and fan 4 to tone 3. As fan 2 and fan 3 were produced by native speakers of Chinese, as a rising contour, they will be compared with tone 2, the Chinese rising tone. Figures 10 to 15 respectively illustrate the production of those segments by the Chinese speakers identified as speakers $08,10,12,16,20$ and 26 . To facilitate comparison, the frequency range for all figures is of 15 semitones.

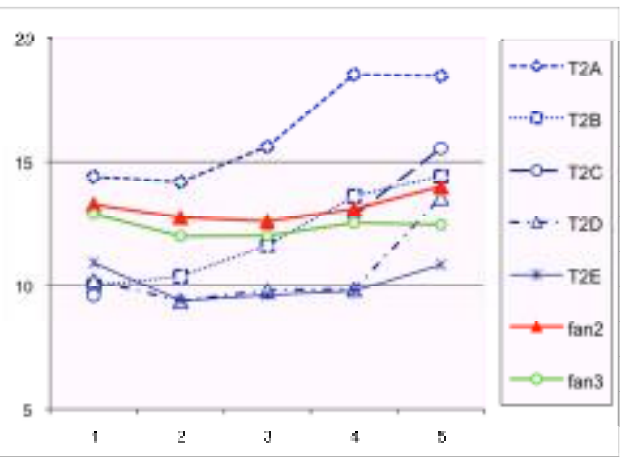

Figure $10 . \mathrm{F}_{0}$ in semitones at $10 \%, 30 \%$, $50 \%, 70 \%, 90 \%$ of fan 2 and fan 3 and of "fán"(tone 2) in five sentential positions in speaker 08.

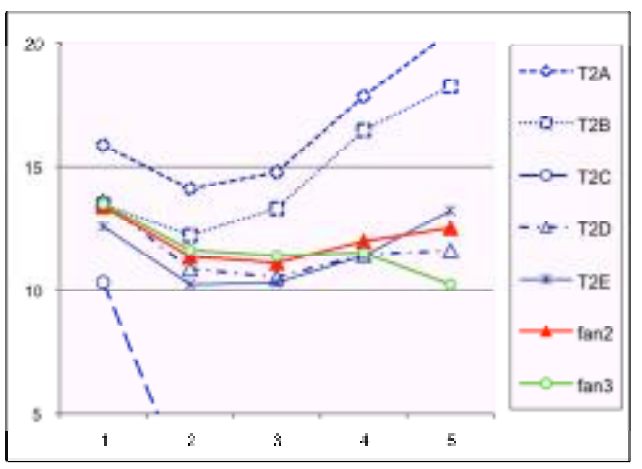

Figure $11 . \mathrm{F}_{0}$ in semitones at $10 \%, 30 \%$, $50 \%, 70 \%, 90 \%$ of fan 2 and fan 3 and of "fán"(tone 2) in five sentential positions in speaker 10 . 


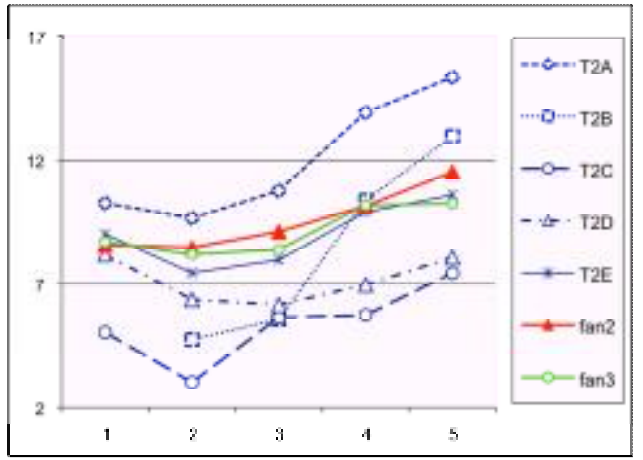

Figure $12 . \mathrm{F}_{0}$ in semitones at $10 \%, 30 \%$, $50 \%, 70 \%, 90 \%$ of fan 2 and fan 3 and of "fán"(tone 2) in five sentential positions in speaker 12 .

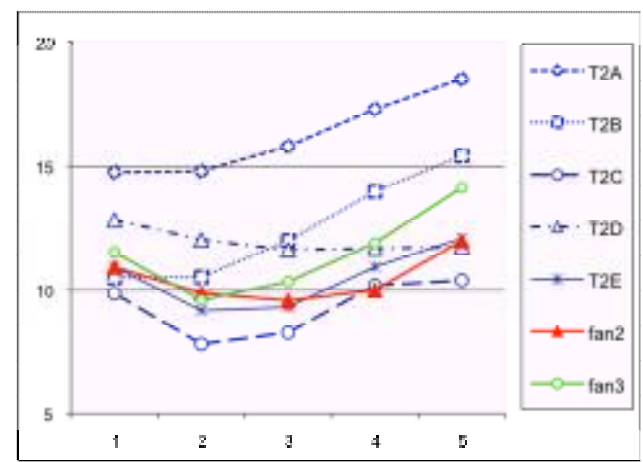

Figure $14 . \mathrm{F}_{0}$ in semitones at $10 \%, 30 \%, 50 \%$, $70 \%, 90 \%$ of fan 2 and fan 3 and of "fán"(tone

2 ) in five sentential positions in speaker 20 .

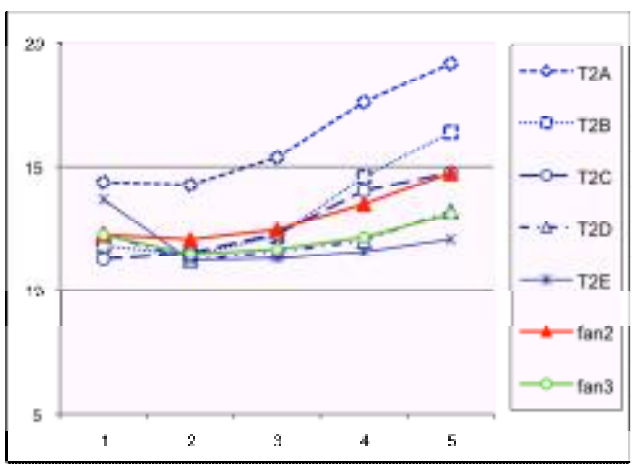

Figure $13 . \mathrm{F}_{0}$ in semitones at $10 \%, 30 \%$, $50 \%, 70 \%, 90 \%$ of fan 2 and fan 3 and of "fán"(tone 2) in five sentential positions in speaker 16 .

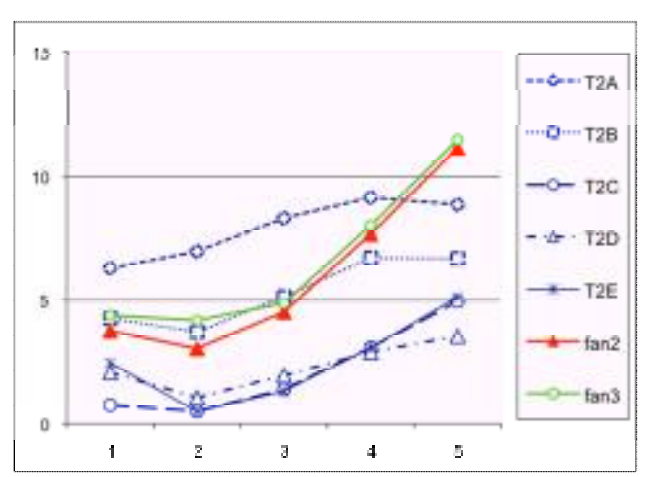

Figure $15 . \mathrm{F}_{0}$ in semitones at $10 \%, 30 \%, 50 \%$, $70 \%, 90 \%$ of fan 2 and fan 3 and of "fán"(tone 2) in five sentential positions in speaker 26.

We noted earlier that the SC group produced fan 2 and fan3 with an almost identical contour and pitch level so that the two contours could virtually superimpose. We can see here that this is not an leveling effect as the similarity in shape and pitch can be observed in the production of the individual speakers. Because the fan 2 and fan 3 segments in the English sentence were pre-pause, we might have expected them to be closer to the production of T2D (tone 2 in pre-pause position). This is not however totally supported by our findings. Indeed, while the contour of T2D is very similar to those of fan 2 and fan3, it is only at the same frequency in two cases (speakers 10 in 16). It can also be noted that the speakers produced fan 2 and fan3 mid-range and with a slight rising contour (except for speaker 26). About the level of pitch, a note of caution should be included in our interpretation because the speakers did not produce the Chinese sentences and the English sentence in the same recording. Indeed, the recordings were done separately and a few minutes apart (English sentences early in the test, Chinese sentences at the end of the 40-minute evaluation) so some speakers might have had different levels of eagerness and fatigue. On the contrary, as all instances of the English "fan" were recorded within the same sentence, the comparison of pitch excursion between fan1, fan2, fan 3 and fan 4 for a same speaker is highly relevant. The same goes for the Chinese sentences as the instances of each tone were recorded within the same recording (i.e. all sentences with tone 1 in one recording, all sentences with tone 2 in another recording and so forth) and the recordings for the different tones were consecutive. In fact, if one sets aside differences of pitch level, T2E (interrogative final in a sentence grammatically marked as interrogative) was extremely close in shape to fan 2 and fan 3 for all speakers.

As fan 1 and fan 4 were produced by native speakers of Chinese, as a low-falling contour, they will be compared with tone 3 , the Chinese falling(-rising) tone. Figures 16 to 21 respectively illustrate the production of those segments by the Chinese speakers identified as speakers $08,10,12,16,20$ and 26. To facilitate comparison, the frequency range for all figures is of 15 semitones. Because the tone used on fan 4 by SC speakers is similar in shape to tone 3 and because fan 4 is affirmative sentence final, it would seem logical to compare it with T3C. However, as explained earlier, measurements for $\mathrm{T} 3 \mathrm{C}$ are highly unreliable. As it turns out, the results yielded by the measurements for fan 4 are also quite unreliable, often because creakiness was produced by the speakers, which would suggest that SC speakers produced, on fan4, a contour similar to what they would produce on a sentence final tone 3 . 


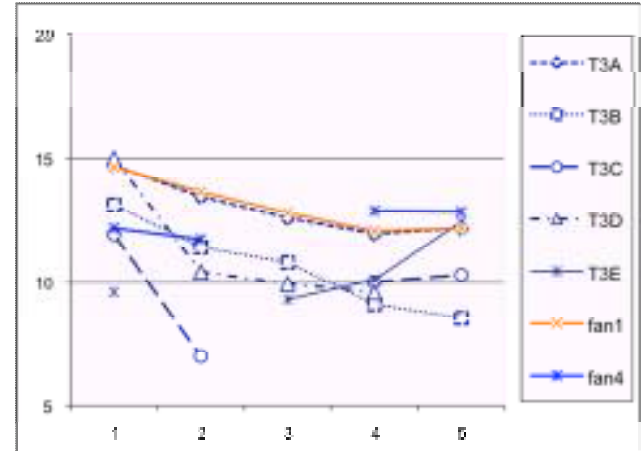

Figure $16 . \quad \mathrm{F}_{0}$ in semitones at $10 \%, 30 \%$, $50 \%, 70 \%, 90 \%$ of fan 1 and fan 4 and of "făn"(tone 3 ) in five sentential positions in speaker 08 .

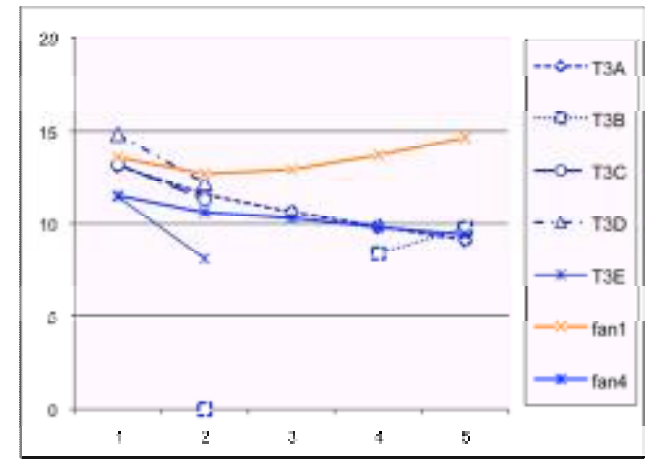

Figure $18, \mathrm{~F}_{0}$ in semitones at $10 \%, 30 \%$, $50 \%, 70 \%, 90 \%$ of fan 1 and fan 4 and of "făn"(tone 3) in five sentential positions in speaker 12.

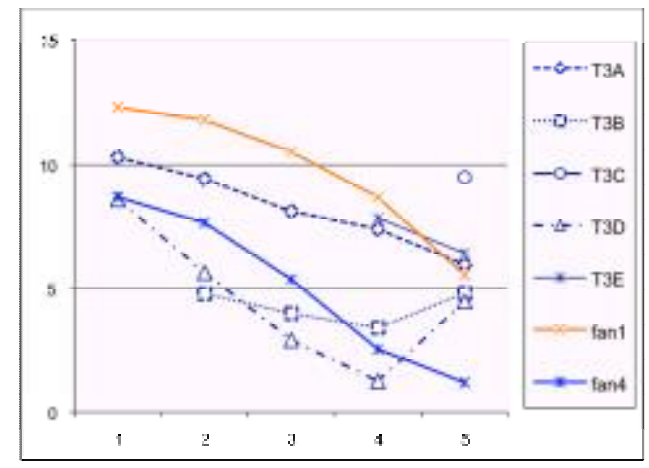

Figure 20. $\mathrm{F}_{0}$ in semitones at $10 \%, 30 \%$, $50 \%, 70 \%, 90 \%$ of fan 1 and fan 4 and of "făn"(tone 3 ) in five sentential positions in speaker 20.

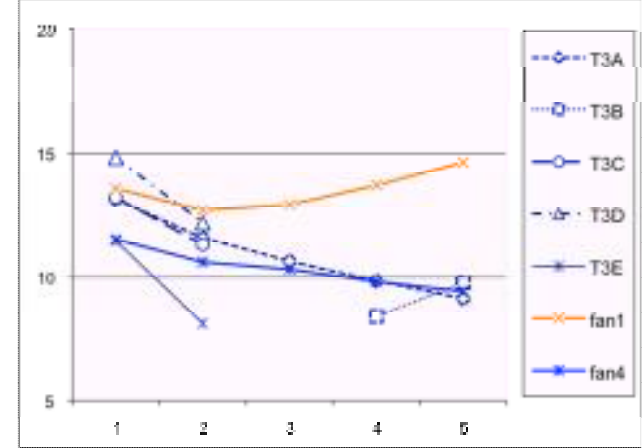

Figure $17 . \mathrm{F}_{0}$ in semitones at $10 \%, 30 \%, 50 \%$, $70 \%, 90 \%$ of fan 1 and fan4 and of "făn"(tone 3 ) in five sentential positions in speaker 10 .

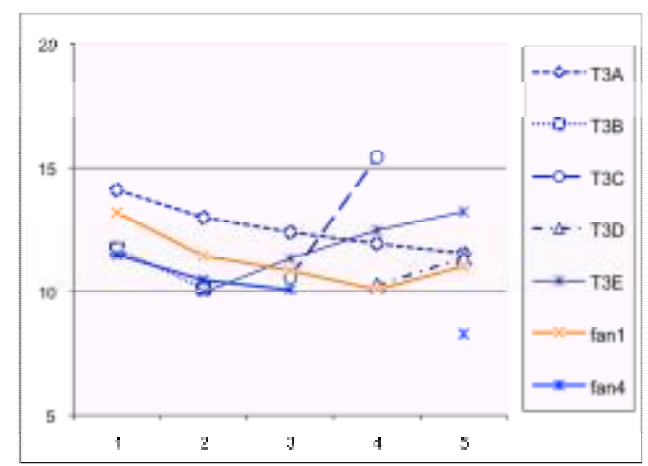

Figure $19 . \mathrm{F}_{0}$ in semitones at $10 \%, 30 \%$, $50 \%, 70 \%, 90 \%$ of fan 1 and fan 4 and of "făn" (tone 3) in five sentential positions in speaker 16.

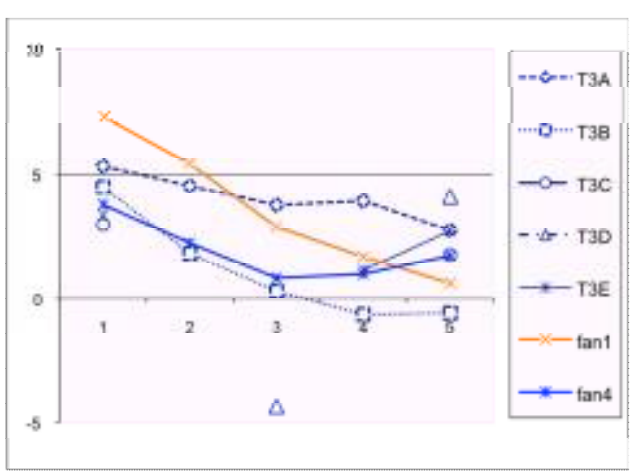

Figure $21 . \mathrm{F}_{0}$ in semitones at $10 \%, 30 \%$, $50 \%, 70 \%, 90 \%$ of fan 1 and fan 4 and of "făn"(tone 3 ) in five sentential positions in speaker 26.

Contrary to the uniformity of contour for fan 2 and fan 3 observed in the previous section, a leveling effect is notable in the contour of fan1. Indeed, the contour for the group (see figure 3) was a low falling tone while in fact two of the speakers (speakers 10 and 12) produced a rising tone, one (speaker 16) produced a falling-rising tone and the other three (speakers 08, 20 and 26) a high falling tone. Although speakers 08 and 16 produced fan1 with a similar contour and pitch to those of one of tone 3 (respectively T3B and T3C), no apparent correlation can be found between individual speakers' production of fan 1 and tone 3 .

With regard to Fan4, we can observe that speakers 10, 12 and 16 produced a low-falling tone, as was observed in the contour for the group (see figure 3). Speaker 20 a high falling tone and speaker 26 a falling-rising tone. The leveling effect is thus at play here, although to a lesser extent than in the case of fan1. We can also observe that fan 4 is fairly similar in shape to T3A. 


\section{Conclusion}

The hypothesis was that Chinese subjects would produce English pitch accents with the Chinese tones whose contour most closely matched the contour of the intended pitch accents.

The experiment confirmed this hypothesis insofar as native speakers of Chinese produced the contour and pitch range of tone 2 to produce all rising pitch accents. Indeed, the production of fan 2 and fan 3 was extremely similar to that of one of the production of T2. The contour of T2E and the instances of "fan" in the English sentence were noted for their high level of similarity. Because of this, and because the Chinese speakers produced almost identical contours for fan2 and fan 3 and at the same frequency, it is possible to entertain the idea that native speakers of Chinese produce pitch accents as Chinese tones.

The results obtained in the second part of the experiment are much less conclusive. Indeed, we found that not all speakers produce the same type of contour for fan 1 and for fan 4 - although one might discern a general falling contour for the latter. Of course, one of the issues here is that these speakers, non-native speakers of English, might not have assimilated the boundary prosodic contour produced at the end of a phrase that introduces a list. The second issue at play here is that these pitch accents were compared to tone 3 , which is very difficult to measure in view of the amount of creak produced with it.

\section{References}

Anani M. (1989) Incorrect Stress Placement in the Case of Arab Learners of English. IRAL. 27:15-22.

Bent T. (2005) Perception and Production of Non-native Prosodic Categories [PhD thesis]. Evanston: Northwestern University.

Chao, Y-R. (1930) “A system of tone-letters”. Le maître phonétique. 45:24-27.

Chen G-T. (1974) The pitch range of English and Chinese speakers. Journal of Chinese Linguistics.2:159-171. (Cited in Wang et al. 2003.)

Chen Y. (2007) From tone to accent: the tonal transfer strategy for Chinese L2 learners of Spanish. Proceedings of $16^{\text {th }}$ International Congress of Phonetic Sciences (ICPhS XVI), Saarbrücken, 2007 August 6-10. :ID1043. Available from: http://www.icphs2007.de/conference/Papers/1043/1043.pdf

Flege J. E. (1995) Second-language speech learning: theory, findings, and problems. In W. Strange, editor. Speech Perception and Linguistic Experience: Issues in Cross-Language Research. Timonium, MD: York Press. p. 229-273.

Guilbault Ch. (2002) The acquisition of French rhythm by English second language learners. [PhD thesis]. University of Alberta.

Guion S. G, Pederson E. (2007) Investigating the role of attention in phonetic learning. In: O.-S. Bohn, M. Munro, editors. Second-language speech learning: The role of language experience in speech perception and production: A festschrift in honour of James E. Flege. Amsterdam: John Benjamins. P57-77.

Guion, S. (2005) Knowledge of English word stress patterns in early and late Korean-English bilinguals. Studies in Second Language Acquisition. 27:503-533.

Hua T-F. (2003) The acquisition of English speech Rhythm by adult Chinese ESL and EFL learners. [PhD thesis]. Manoa: University of Hawaii.

Keating P, Esposito C. Linguistic voice quality. (2007) Department of Linguistics, UCLA. Working Papers in Phonetics. 105-6:85-91. Available from: http://repositories.cdlib.org/uclaling/wpp/No105_6

Kijak A. () How stressful is L2 stress? A cross-linguistic study of L2 perception and production of metrical systems. [PhD thesis]. Utrecht: Universiteit Utrecht; 2009

Lee O. J. (2005) The prosody of questions in Beijing Mandarin. [PhD thesis]. Columbus: Ohio State University.

Mennen I. (2004) Bi-directional interference in the intonation of Dutch speakers of Greek. Journal of Phonetics. 32:543-563.

Miracle W.C. (1989) “Tone production of American students of Chinese: A preliminary acoustic study. Journal of Chinese Language Teachers Association. 24:49-65. (in Wang, 2003)

Nguyen T.A-T, Ingram C.L.J, Pensalfini J. R. (2008) Prosodic transfer in Vietnamese acquisition of English contrastive stress patterns. Journal of Phonetics. 36:158-190.

Ploquin, M. (2009) Phonological Issues in the Production of Prosody by Francophone and Sinophone Learners of English as a Second Language. [PhD thesis]. Montreal: University of Quebec in Montreal.

Saito H, Ueda I. (2007) Does accentuation of L1 transfer to L2 prosody?--A preliminary study on Osaka and Tokyo dialect speakers' pronunciation of English. Proceedings of the 2nd Phonetics Teaching and Learning Conference. London, 2007 August 26. London, University College London .p.1-4.

Shen X. (1990) The Prosody of Mandarin Chinese. Berkeley: University of California Press. 
Swerts M, Zerbian S. (2010) Intonational Differences between L1 and L2 English in South Africa. Phonetica. 67:127146.

Taylor, P.A. (1992) A Phonetic Model of English Intonation. PhD thesis, University of Edinburgh. Published by Indiana University Linguistics Club.

Ueyama M. (2000) Prosodic Transfer: An Acoustic Study of L2 English vs. L2 Japanese. [PhD thesis]. Los Angeles:UCLA.

Wang Y, Jongman A, Sereno J. (2006) Second language acquisition and processing of Mandarin tone. In: Bates E, Tan

L, Tzeng O, editors. Handbook of Chinese Psycholinguistics, Cambridge: Cambridge University Press. p. $250-257$.

\section{APPENDIX A}

fān (tone 1)

First syllable of the sentence: 帆船运动很有趣

fān chuán yùn dòng hěn yǒu qù.

Yachting is very interesting.

Mid sentence/phrase:

\section{我喜欢帆船运动}

wǒ xǐ huān fān chuán yùn dòng

I like yachting.

Last syllable of an affirmative sentence:

\section{一定要撑住帆}

yí dìng yào chēng zhù fān

certain want support the sail

Before a comma :

\section{不但要撑住帆, 还要把好舵。}

Bù dān yào chēng zhù fān, hái yào bă hăo duò.

Not only must support the sail, but also must the good rudder.

Last syllable of an interrogative sentence without the syntactic marker "ma".

你能不能撑帆?

nǐ néng bù néng chēng fān?

Can you support the sail?

fán (tone 2)

First syllable of the sentence: 繁琐的手续让他头疼

Fán suǒ de shǒu xù ràng tā tóu téng

The tedious procedure gave him a headache

Mid sentence/phrase::

登记手续的繁琐让他头疼。

Dēng jì shǒu xù de fán suǒ ràng tā tóu téng.

The tedious registration procedure gave him a headache.

Last syllable of an affirmative sentence:

公司的事让他心烦

gōngsī de shì ràng tā xīn fán

Company business annoyed him.

Before a comma： 不能忍受平凡, 就难以成功

bù néng rěn shòu píng fán, jìu nán yǐ chéng gōng

Cannot endure ordinary, with difficulty succeeds

Last syllable of an interrogative sentence without the syntactic marker "ma".

他是不是很平凡

tā shì bú shì hěn píng fán?

Isn't he very ordinary?

făn (tone 3 ) 
First syllable of the sentence:

返程的票也订好了

Făn chéng de piào yě dìng hăo le

The return trip ticket was also ordered

Mid sentence/phrase:

他没有预定返程 票

tā méi yǒu yù dìng fãn chéng piào

He does not have the predetermined return trip ticket

Last syllable of an affirmative sentence:

这个价格包括往返

zhè gè jià gé bāo kuò wăng fãn

This price is for a round trip

Before a comma：如果包括往返，这个价格就不算贵

rǔ guǒ bāo kuò wăng fãn, jìu bú suàn guì.

If it is for a round-trip, the price is not too high

Last syllable of an interrogative sentence without the syntactic marker "ma".

他们是不是要谋反

tā mén shì bú shì yào móu fãn?

They must plot a rebellion?

Fàn (tone 4)

First syllable of the sentence

饭吃完了, 菜还有一些。

(fàn chī wán le, cài hái yǒu yì xiē.)

The food eaten, vegetable also has some.

Mid sentence/phrase:

他喝完酒以后, 没吃饭就走了

(tā hē wán jiǔ yǐ hòu, méi chī fàn jiù zǒu le.)

He left after drinking alcohol and not eating.

Last syllable of an affirmative sentence:

他光吃菜, 不吃饭

(tā guāng chī cài, bù chī fàn.)

He only eats vegetables, not rice.

Before a comma：我们去吃饭，好不好？

(wǒ men qŭ chī fàn, hăo bù hăo)

Let's go for a meal, shall we?

Last syllable of an interrogative sentence without the syntactic marker "ma".

你昨天晚上吃的什么饭?

(nǐ zuó tiān wăn shàng chī de shén me fàn?)

Did you have anything to eat last night? 